\title{
OSTEOCHONDRITIS DISSECANS OF THE KNEE: DIAGNOSIS AND TREATMENT
}

\section{ABSTRACT}

Osteochondritis dissecans (OCD) is a pathological process affecting the subchondral bone of the knee in children and adolescents with open growth plates (juvenile OCD) and young adults with closed growth plates (adult OCD). It may lead to secondary effects on joint cartilage, such as pain, edema, possible formation of free bodies and mechanical symptoms, including joint locking. OCD may lead to degenerative changes may develop if left untreated. This article presents a review and update on this problem, with special emphasis on diagnosis and treatment. The latter may include either conservative methods, which show more predictable results for juvenile OCD, or various surgical methods, which include reparative techniques like isolated removal of the fragment, bone drilling and fixation of the osteochondral fragments, and restorative techniques like microfractures, autologous osteochondral transplantation (mosaicplasty), autologous chondrocyte implantation and fresh osteochondral allograft, depending on lesion stability, lesion viability, skeletal maturity and OCD process location. Recent assessments on the results from several types of treatment have shown that there is a lack of studies with reliable levels of evidence and have suggested that further multicenter prospective randomized and controlled studies on management of this disease should be conducted.

Keywords - Knee Joint; Cartilage, Joint; Osteochondritis Dissecans

\section{INTRODUCTION}

Osteochondritis dissecans (OCD) of the knee is a relatively common cause of pain and functional limitation among children and young adults. It is an acquired pathological condition in which the subchondral bone becomes avascular, thus destabilizing the chondral coverage. If the process is not reversed (consolidation), the bone-cartilage complex may separate completely from its bone bed when subjected to impact and shearing forces ${ }^{(1)}$, which gives rise to joint irregularity and even formation of free bodies.

OCD of the knee can be subdivided into two forms: juvenile osteochondritis dissecans (JOCD) and adult osteochondritis dissecans (AOCD), according to whether it occurs in patients with an open or closed growth plate, respectively ${ }^{(2)}$. The distinction between the two forms is important from the point of view of treatment and prognosis. When there is no satisfactory response to treatment, both forms present a tendency towards late sequelae, including osteoarthrosis (OA).

In this updating article, emphasis will be placed on the most recent advances relating to diagnosis and treatment of OCD, given that its history and in-depth discussions on its etiology are very well presented in established textbooks.

\section{HISTORY AND ETIOLOGY}

König (1881) was the first author to use to term osteochondritis dissecans, although Paget (1870) had considered this lesion to be a form of quiet necrosis. Initially, König described the process as inflammatory, but reconsidered his affirmation in $1926^{(3)}$.

A variety of hypotheses have been put forward regarding the etiology of OCD, including trauma, ischemia and genetic and endocrine factors ${ }^{(4)}$.

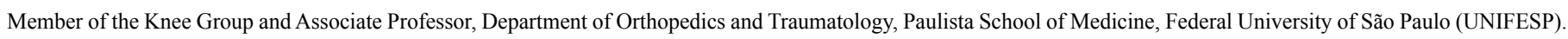

Work developed in the Department of Orthopedics and Traumatology, Paulista School of Medicine, Federal University of São Paulo (UNIFESP).

Correspondence: Rua Áurea 463, ap. 112, Vila Mariana, 04015-070 São Paulo, SP, Brazil. E-mail: mestrinerla@terra.com.br

Work received for publication: January 4, 2012; accepted for publication: January 9, 2012.

The authors declare that there was no conflict of interest in conducting this work 
The commonest location for OCD (posterolateral face of the medial femoral condyle) suggests that it has a traumatic cause, such as internal rotation of the tibia due to impact of the tibial spine against the medial condyle ${ }^{(5)}$ or repeated microtrauma with possible impairment and interruption of the local circulation, or even dissection and possible detachment of a subchondral fragment ${ }^{(6)}$. In addition to this, there are the shearing forces generated at the time of internal tibial rotation and knee flexion.

Recent studies have, in some way, corroborated the propositions of Smillie ${ }^{(7)}$, who postulated different etiologies for JOCD and AOCD, such that traumatic causes would be more directly related to AOCD and possible abnormalities of ossification to JOCD. It has been accepted that repeated microtraumas may cause fractures of the subchondral bone (stress fractures), thus compromising the vascular supply to the area of the lesion ${ }^{(1)}$. A correlation has also been made between OCD of the lateral condyle (rare) and presence of a discoid meniscus ${ }^{(8)}$.

Through vascular factors (ischemic theory), it is sought to establish an analogy between osteonecrosis and OCD. Poor end-arterial circulation of the distal femur is considered to be a predisposing factor ${ }^{(9)}$. Other authors have contested this theory because they did not detect this vascular deficiency and because they did not observe any histological evidence of bone necrosis.

With regard to genetic and constitutional factors, the observations of Ribbing ${ }^{(10)}$, on epiphyseal dysplasia, and Mubarak and Carroll ${ }^{(11)}$, on familial predisposition, are important. However, Petrie ${ }^{(12)}$ did not observe any clear evidence of familial genetic patterns.

The irregularities of ossification during epiphyseal maturation become resolved spontaneously and when this does not occur, these abnormalities may predispose towards imbalance relating to rapid proliferation of cartilage ${ }^{(13)}$. However, some authors accept that accessory nuclei may become separated from this epiphyseal area and may be precursors of $\mathrm{OCD}^{(12)}$.

\section{DIAGNOSIS}

The clinical condition presents certain variations according to the severity and stability of the lesion. The basic complaint is pain and edema in the affected knee, which may be exacerbated by physical activity. Mechanical symptoms such as crepitation, clicks and even joint blockage may occur in cases of free joint bodies.
The process is presented between the ages of 13 and 21, and JOCD and AOCD can be differentiated through analyzing the bone age at the start of the symptoms, such that the growth plate is considered to be open in cases of JOCD and closed in cases of $\mathrm{AOCD}^{(2,4)}$.

The physical signs may be related to the lesion site. The sites most commonly affected are the posterolateral face of the medial femoral condyle (75\%), the loading zone of the medial and lateral femoral condyles $(20 \%)$ and the patellar surface $(5 \%)^{(14,15)}$. However, this distribution varies, according to some authors ${ }^{(16)}$.

Wilson ${ }^{(17)}$ considered that external rotation during gait was a form of compensation for avoiding the discomfort caused by the impact of the tibial spine against the lateral wall of the medial femoral condyle. Wilson's maneuver reproduces the pain through internal rotation of the tibia during knee extension, starting from $90 \%$ flexion. The pain is alleviated through external rotation.

The diagnostic value of this maneuver has been questioned when correlated with radiographic findings ${ }^{(18)}$. However, when positive ( $25 \%$ of the cases), it becomes important for proceeding with semiological analysis.

Atrophy of the quadriceps may be present in symptomatic cases of long duration. Mechanical symptoms may appear with the evolution of the process and are more associated with instability of the lesion.

OCD of the patella is rare $(5 \%)^{(19)}$ and occurs predominantly in males. The symptoms are poorly defined, with diffuse pain that is worsened by placing weight on the limb and flexion. Edema during or after excessive activities and early muscle atrophy are signs that may occur in association with retropatellar crepitation. This lesion is best observed in lateral and axial radiographic views, and it is located distally and preferentially in the medial facet ${ }^{(20)}$. Computed tomography and magnetic resonance imaging are important for defining the location, extent and viability of the lesion.

\section{Image analysis}

Protocols for image analysis in OCD cases may serve for diagnosing the condition, establishing the prognosis with regard to the type of treatment, and for monitoring whether the process becomes resolved.

Simple radiographic examinations, computed tomography (CT) and magnetic resonance imaging (MRI) are the most important types of examination. Scintigraphy using technetium 99 can be used, including 
for evaluating the trend towards resolution of the process $^{(21)}$. However, this technique has been questioned because of the time taken for obtaining the images and the risk from administration of contrast.

Simple radiographic examination should take into consideration the anteroposterior, lateral and axial views of the patella. The posteroanterior view at between 30 and 50 degrees of flexion (tunnel) is particularly important for analyzing lesions that are typically located in the lateral wall of the medial femoral condyle (Figure 1-A, B and C). The alpha-

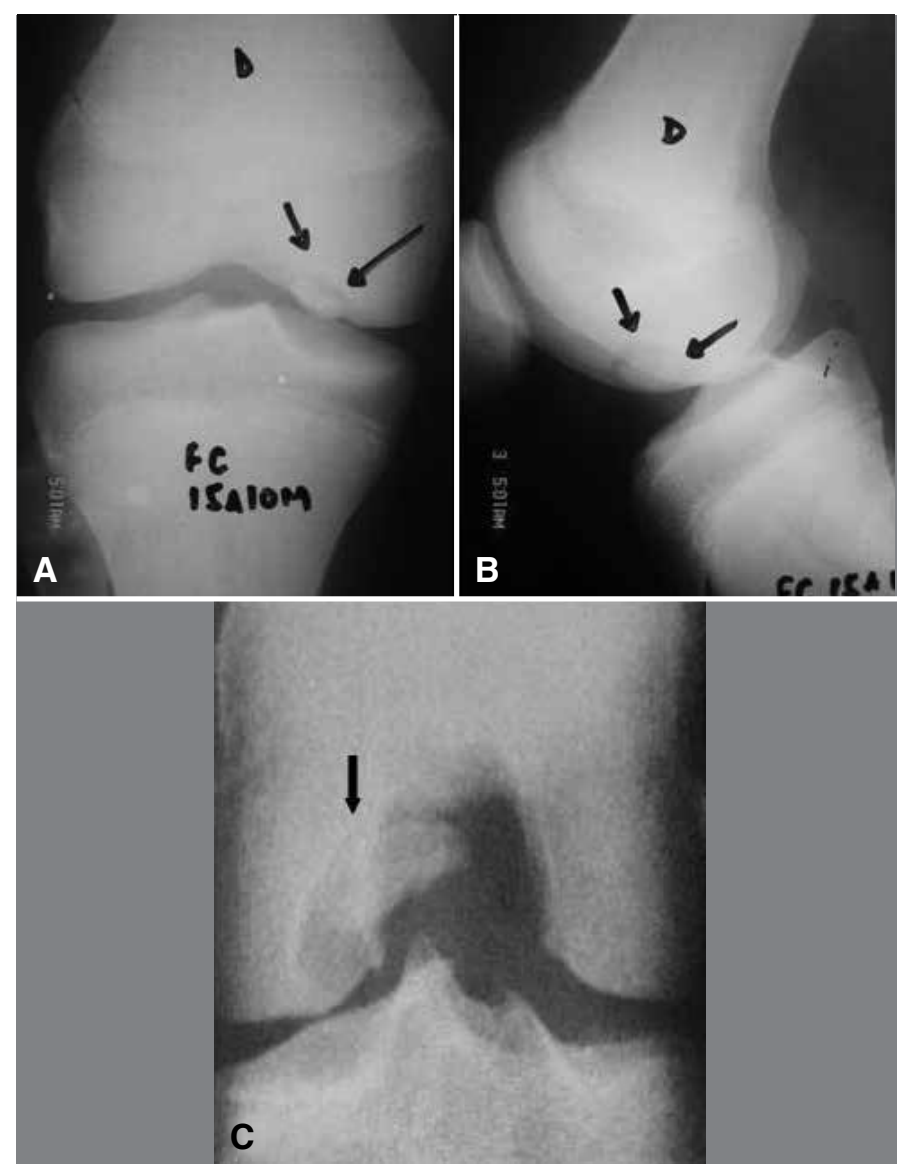

Figure 1 - Radiographic examination of the classical location for OCD on the posterolateral face of the medial femoral condyle. (A) Anteroposterior view. (B) Lateral view. (C) Posteroanterior view (tunnel). numerical radiographic classification ${ }^{(22)}$ based on the location of the lesion is valuable for scientific and research documentation.

The greatest application of CT is in relation to revealing the location and dimensions of the lesion.

MRI is currently the most important examination, because it enables analysis on bone quality, edema, possible subchondral separation and cartilage condition $^{(23)}$. Four assessment criteria have been established and if these are fulfilled, the resultant sensitivity and specificity are $97 \%$ and $100 \%$ respectively ${ }^{(24)}$.

The high signal lines (T2-weighted images) may represent both granulation tissue in the resolution phase and the presence of subchondral fluid, which serve as criteria denoting instability (Figure 2-A, B and C):

- Well demarcated high-signal line greater than or equal to $5 \mathrm{~mm}$ surrounding the lesion;

- Area of homogenous high signal greater than $5 \mathrm{~mm}$ around the lesion;

- Focal defect greater than $5 \mathrm{~mm}$ on the joint surface; and

- High-signal line crossing the joint surface and subchondral bone.

Techniques using contrast medium (gadolinium 153) are inconclusive, but the more recent methods that are specific for cartilage have made it possible to establish the degree of chondral damage, including biochemical alterations, as well as the differentiation between fluid, interposed synovial tissue, presence of fibrocartilage and compromised subchondral bone ${ }^{(4,25)}$.

It is important to bear in mind that, especially in relation to JOCD, the normal variations in ossification nuclei $^{(26)}$ may cause errors of interpretation among younger patients, independent of the imaging examination used.

Use of arthroscopy has contributed towards diagnosing, staging and treating OCD. Arthroscopy should be used in association and in comparison with other diagnostic methods. The analysis criteria for MRI
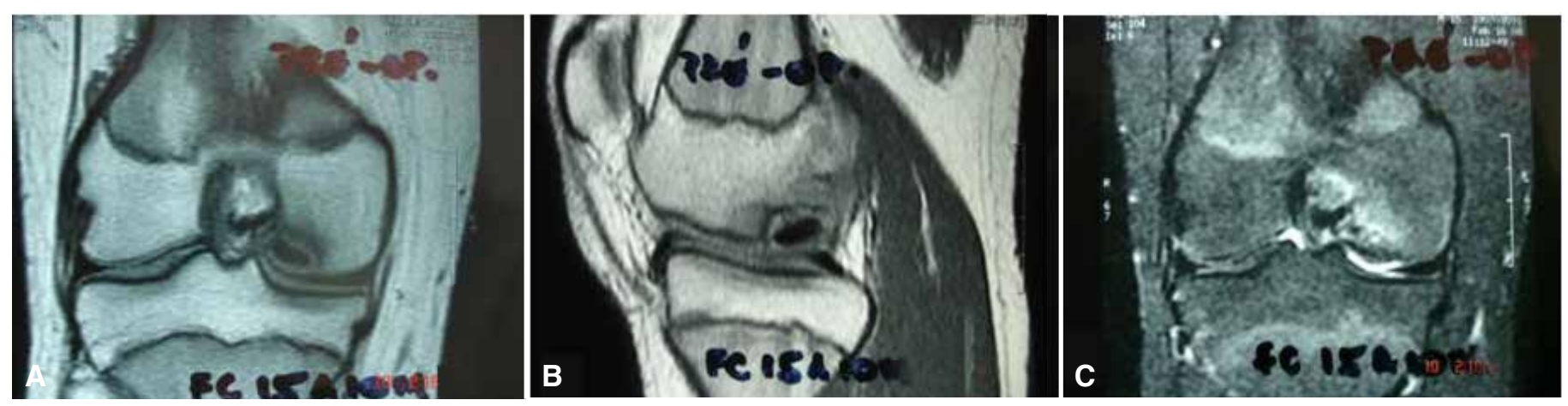

Figure 2 - Magnetic resonance imaging on an OCD lesion (classical location). (A) Coronal plane (T1). (B) Sagittal plane (T1). (C) Coronal plane (T2). 
show good precision compared with arthroscopic analysis, according to Guhl's intraoperative classification $^{(14)}$ which defines the integrity and stability of the fragment (Figure $3-\mathrm{A}, \mathrm{B}$ and $\mathrm{C}$ ):

- Type I - Cartilage intact. Softening.

- Type II - Cartilage fissure. Stable fragment.

- Type III - Partial detachment (hinged lesion).

- Type IV - Osteochondral crater and free body.

The decision regarding the type of additional treatment should not be limited to a single system. The dimensions and number of loose fragments, the presence of associated bone fragments and their potential capacity for consolidation and the patient's age (JOCD or AOCD) are factors that should be assessed in order to choose the type of treatment ${ }^{(4)}$.

\section{Treatment and prognosis}

Analysis on the results and the prognosis for conservative and surgical treatments of OCD shows that there is a lack of reliable randomized controlled clinical trials. In general, the approaches used take into consideration the maturity of the growth plate, situation of the subchondral bone, stability of the lesion, dimensions of the fragment and integrity of the cartilage.

The natural history of untreated OCD is not well defined, including in relation to the evolution to degenerative arthropathy. It has been accepted that JOCD has a greater tendency towards resolution, especially among younger patients ${ }^{(16,27-29)}$.

Regarding evolution, retrospective studies with more than 30 years of follow-up ${ }^{(30,31)}$ have shown that patients who present the lesion after closure of the growth plate (AOCD) show a degenerative process in $50 \%$ of the cases, and 10 years earlier than among the general population. These studies have also shown that lesions of the lateral femoral condyle have the worst prognosis.
The treatment approaches need to be analyzed cautiously, since they are based on studies with level of evidence IV or $\mathrm{V}^{(4)}$. The options vary according to whether the lesions are stable, unstable, viable or unviable. The methods may be conservative or surgical, and in the latter, the procedures are considered to be either reparative or restorative $\mathrm{e}^{(15,24,32)}$.

The aims of the treatment are to conserve the cartilage when possible, or to use restoration processes.

\section{Conservative treatment}

Conservative treatment is more frequently successful (i.e. it resolves the process) if performed before the growth plate closure. Stable lesions have a better prognosis.

The guidance includes analgesic and anti-inflammatory medication, load reduction (use of crutches), use of an immobilizer and even the classical techniques of use of plaster casts. The latter has been criticized because of the risk that this could predispose towards chondral degeneration and joint stiffness. Total restriction of physical activities may lead to resolution of the process among younger patients ${ }^{(33)}$. Satisfactory results have also been demonstrated in $50 \%$ of the cases of JOCD through restriction of impact activities but not of mobilization or weight-bearing activities, as well as through muscle exercises (quadriceps) ${ }^{(2,18)}$.

The duration of conservative treatment has not been clearly established, but it probably should not be prolonged beyond six months if there is no evidence of resolution clinically or through imaging examinations ${ }^{(15,32)}$.

It is important to emphasize that adherence to conservative treatment is fundamental for success. This is not always possible with young and active patients with JOCD, which has led to consideration of approaches consisting of conservative treatment followed by procedures that are more invasive ${ }^{(34)}$.
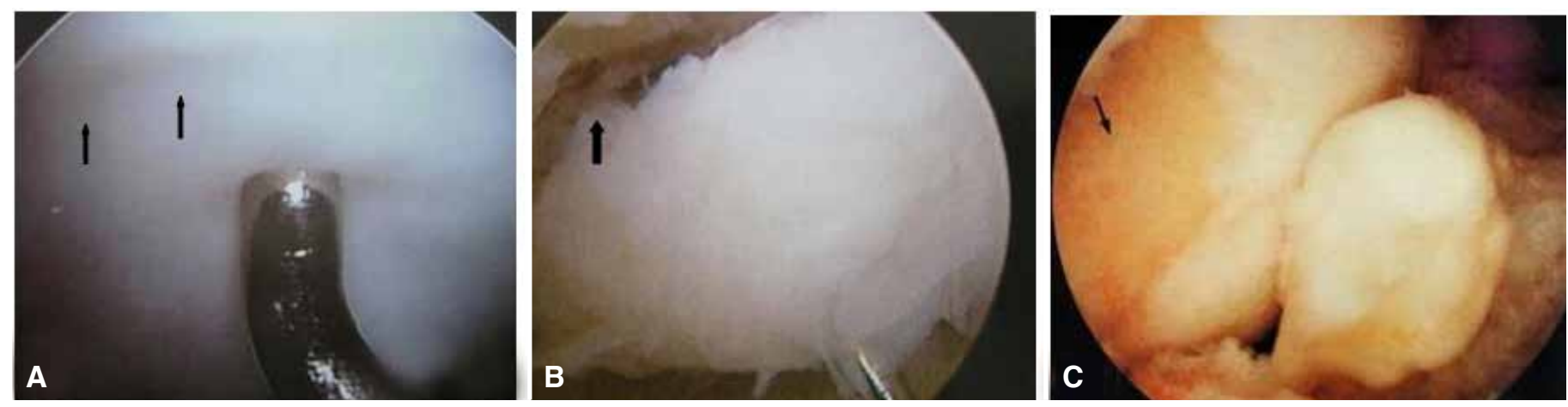

Figure 3 - Arthroscopic examination on OCD lesions. (A) Softening (arrows indicate the limits of the lesion). (B) Partial detachment of the lesion (arrow). (C) Free body and crater (arrow). 


\section{Surgical treatment}

Surgery is indicated in cases in which conservative treatment fails, and in cases of unstable or dislocated lesions $^{(14)}$, especially for AOCD. The surgical options include simple removal of the fragment or possible free body, simple drilling of the subchondral bone, fixation of the fragment, microfracturing, osteochondral autografts, allografts and autologous implantation of chondrocytes ${ }^{(2,35)}$.

\section{Stable lesions}

In cases of stable lesions, the objective of the treatment is to promote a reparative response from the subchondral bone ${ }^{(15,23,24)}$.

Drilling can be done arthroscopically in an anterograde transarticular manner through using fine wires (Kirschner) or in a retrograde transphyseal manner with the aid of fluoroscopy, which is technically more difficult but has the advantage of not compromising the joint cartilage. There is also, in such cases, the possibility of using a graft to provide a greater reparative stimulus ${ }^{(36)}$.

Following the same approach, Friel et al ${ }^{(24)}$ proposed that arthroscopic evaluation should be done on stable lesions, even if imaging examinations have already shown that fluid is present between the fragment and the bed. The lesion is detached in a hinged manner, local fibrosis is debrided, drilling is performed in an anterograde manner and the fragment is fixed using one or two biodegradable compression screws. Other forms of prophylactic fixation, including with reparative stimuli will be presented below, for cases of unstable lesions.

During the postoperative period, patients should be kept without weight borne on the limb for up to four weeks. Following this, weight-bearing is progressively allowed through rehabilitation physiotherapy until around the fourth to sixth month, when a gradual return to physical activities is allowed, if the patient is asymptomatic.

The results tend to be better, with pain relief and radiographic signs of resolution, in younger patients (JOCD). Unsatisfactory results are related to atypical lesion locations, multiple lesions and presence of comorbidities ${ }^{(37)}$.

\section{Unstable lesions}

Conservative treatment is generally not indicated for unstable lesions, since there is the risk that via- ble lesions may be transformed into unviable lesions, with formation of free bodies, and the potential risk of a more severe lesion in the remaining cartilage. Independent of age, patients with clinical and imaging evidence of unstable OCD should be treated surgically.

Viable lesions are those that have a great potential for reestablishment in their subchondral bed, while maintaining joint congruence. These include lesions of flap or hinge type.

Unviable lesions are those that cannot be conserved and stabilized because they present in the form of free bodies or because of fragmentation (Figure $3-\mathrm{A}, \mathrm{B}$ and $\mathrm{C}$ ), and consequently because of the impossibility of reestablishing joint congruence.

Whatever the situation is, the aim of surgical treatment is to reestablish the regularity of the joint surface using reparative techniques in cases of viable lesions, or using reconstructive techniques for unviable lesions ${ }^{(15)}$.

\section{Removal of fragments or free bodies}

Removal of fragments that are considered to be unstable $^{(38)}$, performed as the sole procedure, may be indicated in a small number of cases in which these fragments are avascular and comminutive, with an insufficient subchondral component, or in chronic cases in which the fibrous tissue impedes replacement and stabilization. Association with reparative techniques such as drilling has shown satisfactory results in $72 \%$, especial in cases of lesions smaller than $2 \mathrm{~cm}^{2(39)}$. However, there is some controversy regarding the results, and they may be considered for short-term follow-up ${ }^{(27,40)}$. Simply removing the fragment reduces the possibility of lesion progression and this procedure is reserved for patients with low functional demands or those who do not demonstrate adequate adherence to longer-term special rehabilitation protocols.

\section{Reparative techniques}

Reparative techniques have the aim of maintaining or reestablishing the integrity and congruence of the osteochondral fragment.

\section{Drilling}

As described earlier, this technique alone is greatly indicated for stable fragments, based on MRI examinations or arthroscopic evaluation ${ }^{(14)}$. In cases of instability of the fragment, various fixation techniques can often be called upon. 


\section{Fixation of fragments}

Reduction (replacement) of the fragment and some type of arthroscopic or open fixation is indicated for cases of unstable lesions, with a sufficient subchondral component, independently for JOCD and AOCD ${ }^{(2,36)}$.

The lesions are often known to be in flap or trapdoor form, and they may be partially raised from their bed for curettage of subchondral bone drilling, for vascular stimulation. Restorative techniques such as microfracturing ${ }^{(41,42)}$ and use of bone grafts for support before fixation may be indicated ${ }^{(1,43)}$.

Fixation is generally anterograde (Figure 4) and may be achieved using a variety of methods with Kirschner wires, cannulated screws with partial threading (Herbert) or full threading (Accutrak), biodegradable arrows or screws and cortical or osteochondral bone $\operatorname{arrows}^{(16,24,44)}$.

The advantage of fixation using screws is the compression that can be applied, which mechanically and biologically favors consolidation. However, removal of the material after around eight weeks is recommended so as to avoid lesions in the opposing cartilage, and the resolution of the process can be evaluated at this time ${ }^{(32)}$.

Biodegradable fixation materials (screws, arrows or smooth or barbed pins) have been recommended in order to avoid a second removal process, but criticism remains regarding the degree of compression that they promote, because they continue in situ until

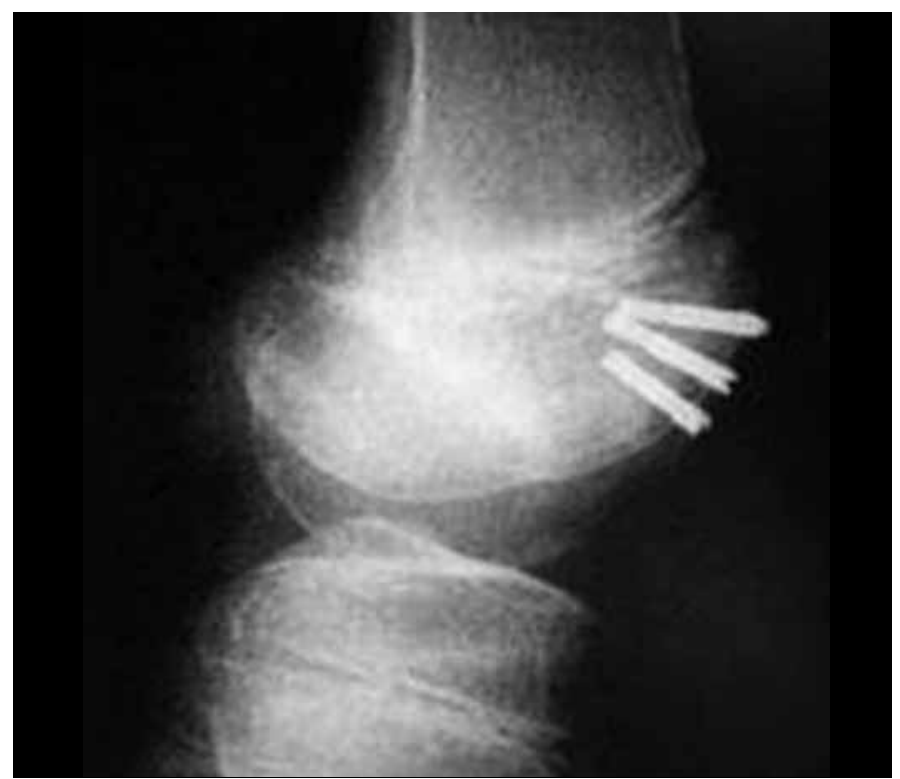

Figure 4 - Postoperative radiographic examination (lateral view). Fixation and compression of the OCD fragment using metal screws. enzymatic degradation occurs ${ }^{(45)}$ and aseptic synovitis occurs due to a foreign-body reaction ${ }^{(32)}$.

The results are variable, and comparative analysis between cannulated screws, fully or partially threaded screws, arrows and biodegradable pins has not shown statistically significant differences.

Retrograde fixation may be an option, especially for cases of OCD of the patella, for which auxiliary use of fluoroscopy is fundamental.

Open or arthroscopic fixation using autologous cortical bone arrows and pins, including use of special instruments, has shown satisfactory results ${ }^{(46-48)}$ (Figure $5-\mathrm{A}$ and $\mathrm{B}$ ).

Based on analysis on the good results, in situ arthroscopic fixation techniques are indicated for preserving and maintaining joint congruence, especially for skeletally immature patients (JOCD) $)^{(49,50)}$.
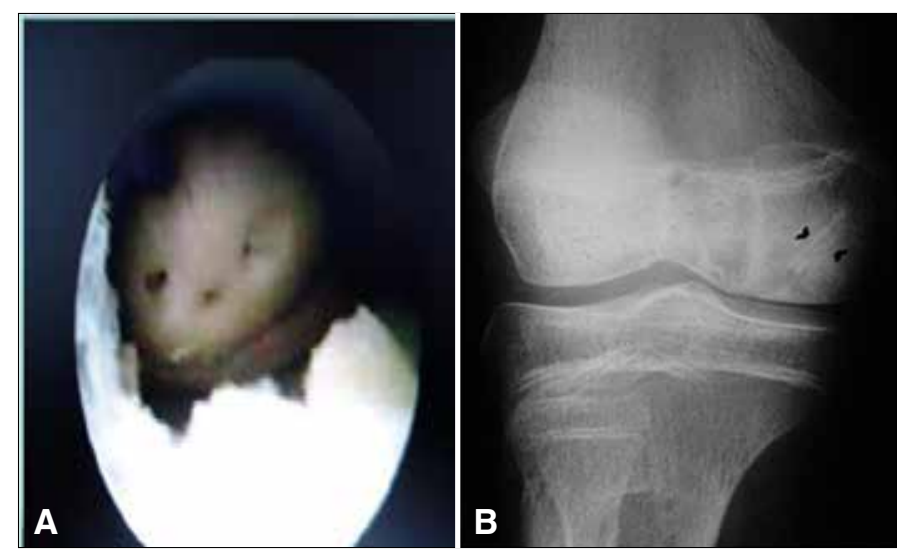

Figure $\mathbf{5}$ - Fixation of OCD lesion using bone sticks. (A) Appearance seen via arthroscopy. (B) Radiographic image (anteroposterior): arrows indicate the bone sticks.

\section{Restorative techniques}

Restorative techniques are indicated as an option for cases of unstable lesions in which the results from reparative techniques were unsatisfactory, or for unstable lesions with the aim of reestablishing joint regularity and congruence.

\section{Microfracturing}

Microfracturing was introduced by Steadman et $a l^{(51)}$ and consists of production of small fractures through impaction of the subchondral bone. It is considered to be the first option because it is simple and minimally invasive. The lesion is debrided with removal of the calcified zone and, using a drill or special spike, several orifices are made in its base, thereby causing medullary bleeding and formation 
of coagulum with undifferentiated mesenchymal cells and giving rise to formation of fibrocartilage (collagen type II) of biomechanical characteristics that are inferior to those of hyaline cartilage. Microfracturing is ideally indicated for lesions of dimensions smaller than $4 \mathrm{~cm}^{2}$ (Figure 6).

Restriction of weight-bearing (six weeks) in association with continual active and passive movement is essential according to Steadman et $a l^{(51)}$, who showed satisfactory results from an 11-year follow-up ${ }^{(52)}$. However, a systematic analysis on 28 studies involving 3,122 patients showed inconclusive results from follow-ups longer than two years ${ }^{(53)}$.

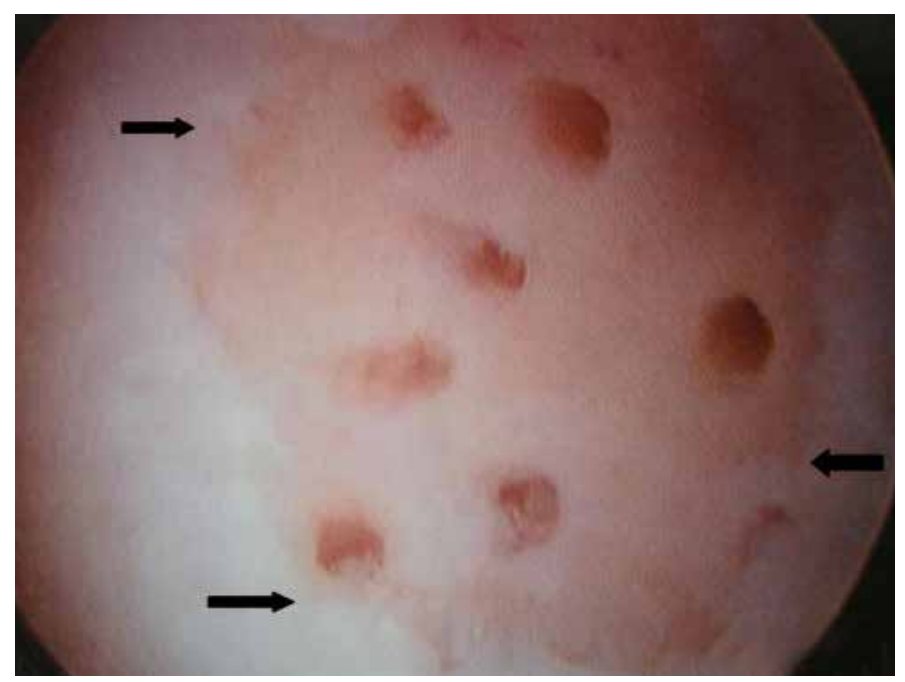

Figure 6 - Arthroscopic view of treatment of a subchondral OCD lesion by means of microfracturing: arrows indicate the limits of the lesion.

\section{Autologous osteochondral transplantation}

Autologous osteochondral transplantation or mosaicplasty is indicated for cases of larger lesions with compromised subchondral bone integrity, for which microfracturing has been shown to be insufficient ${ }^{(54)}$. This involves removal of osteochondral cylinders from a region with low load impact (generally the lateral margin of the femoral trochlea or the area above the intercondylar sulcus) and their transfer to the area of the lesion by means of special instruments (Figure 7). The number of cylinders transplanted depends on the dimensions of the lesion (mosaicplasty) ${ }^{(55)}$.

Good results from this technique have been demonstrated by several authors, ranging from 79 to $94 \%$, with a minimum follow-up of 18 months and radiographic evidence of graft integration ${ }^{(56,57)}$, using open or arthroscopic methods, independent of skeletal maturity.

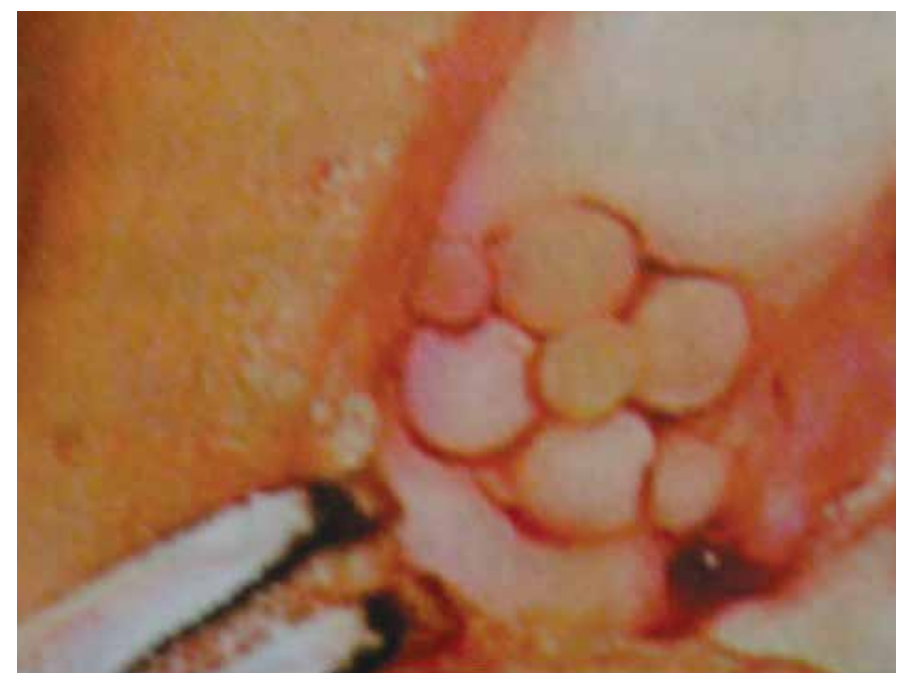

Figure 7 - Final appearance of treatment of an OCD lesion by means of arthrotomy and autologous osteochondral transplantation (mosaicplasty).

The limitations of this method relate to the dimensions of the lesion, donor sources and morbidity of the donor zone.

\section{Autologous implantation of chondrocytes}

Autologous implantation of chondrocytes is indicated for single osteochondral lesions of dimensions greater than $10 \mathrm{~cm}^{2(58)}$. The technique is carried out in two stages, with initial removal of a cartilage sample by means of arthroscopy. The chondrocytes are cultivated in vitro for three to four weeks and then, in the second procedure, they are implanted in the lesion after preparation of the bed. The latter is sealed by means of a periosteal membrane that is sutured for containment (Figure 8).

The clinical results after follow-ups ranging from two to ten years have been shown to be satisfactory in 71 to $91 \%$ of the cases ${ }^{(39,58-60)}$, especially for JOCD and in lesions of dimensions less than $6 \mathrm{~cm}^{2}$. In larger lesions (between 8 and $10 \mathrm{~cm}^{2}$ ), the implantation can be done, either concomitantly or not, in association with a bone graft filler after debridement and drilling, or the double layer technique (periosteal sandwich) can be used ${ }^{(44,61,62)}$.

The results relating to the type of cartilage obtained after microfracturing, autologous osteochondral transplantation and autologous implantation of chondrocytes have been divergent. Many authors have accepted that microfracturing gives rise to fibrocartilage (collagen type II), which also occurs in the spaces between the mosaicplasty cylinders.

In relation to autologous implantation of chon- 


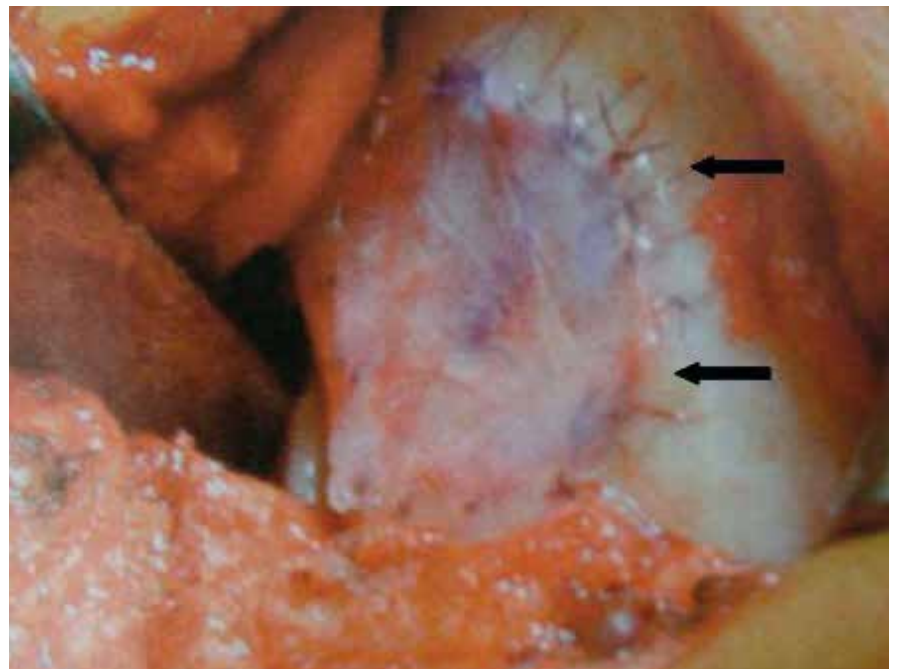

Figure 8 - Final appearance of treatment of an OCD lesion by means of arthrotomy and autologous implantation of chondrocytes. Note the suture in the periosteal membrane (arrow).

drocytes, the neoformed cartilage presents hyaline cartilage components with similar morphology but with a surface layer of fibrocartilage. For this reason, it is only considered to be hyaline-like. LaPrade et $a l^{(63)}$ analyzed biopsies from patients undergoing autologous implantation of chondrocytes, and observed the presence of fibrocartilage, without evidence of integration with surrounding tissue, and considered that the term hyaline-like was inadequate.

Recent studies conducted using characteristic chondrocyte implantation, which uses a technique to select chondrocytes capable of producing hyaline-like cartilage $^{(64)}$, may present better clinical results with longer follow-ups.

A comparison between microfracturing, autologous osteochondral transplantation and autologous implantation of chondrocytes was conducted recently by Safran and Seiber ${ }^{(65)}$, using systematic analysis on studies with level I and II evidence ${ }^{(59,64,66-68)}$. Meta-analysis was impossible because of the variety of result assessment methods, and thus it was also impossible to conclude that any given procedure was superior to any other.

\section{Osteochondral allografts}

Fresh allografts are obtained and prepared in accordance with the shape and dimensions of the OCD lesion, which should also be prepared to receive the graft $^{(69,70)}$. To ensure graft stability, a variety of fixation methods can be used, such as metal or biodegradable compression screws.

The postoperative treatment is similar to what is used for autologous osteochondral transplantation and autologous implantation of chondrocytes. The results have been uniformly satisfactory, taking into account a reasonable length of follow-up ${ }^{(69,71-73)}$.

Allografts are generally reserved for cases of AOCD. The disadvantages of this technique include cost, graft availability and viability and the possibility of disease transmission ${ }^{(15)}$.

With the aim of creating guidelines for diagnosing and treating OCD, the American Academy of Orthopedic Surgeons (AAOS) instituted a committee to systematically review the literature on this subject ${ }^{(74)}$. Sixteen recommendations were reported: four for diagnosis and 12 for treatment. Based on the levels of evidence of the studies analyzed, the recommendations were classified as strong (none), moderate (none), weak (two), inconclusive (ten) and consensus (four).

The committee members concluded that although OCD detection had evolved in relation to last century, the natural history of the lesion remained unclear and the appropriate treatment remained incompletely defined. They considered that only 16 studies were of sufficient quality to establish the guidelines for clinical practice, and these included the studies by Kocher et $a l^{(75)}$, Kocher et $a l^{(76)}$ and O'Connor et $a l^{(77)}$. They suggested that future studies should include inter and intra-observer analyses, prospective cohort studies and randomized controlled trials, preferably of multicenter nature.

\section{CONCLUSIONS}

OCD of the knee should be considered to be a differential diagnosis among children, adolescents and young adults with acute or subacute knee pain.

The history, physical examination, imaging examinations (especially MRI) and arthroscopy are important for early diagnosis and conservative or surgical management of the process aimed at preserving the cartilage and joint congruence. When this is not possible, a variety of restorative techniques can be used.

However, the rarity of the process and the lack of studies with more reliable levels of evidence indicate that future studies should be multicenter, prospective randomized controlled studies, with the aim of establishing the ideal guidelines, both for diagnosis and for treatment. 


\section{REFERENCES}

1. Magnussen RA, Carey JL, Spindler KP. Does operative fixation of an osteochondritis dissecans loose body result in healing and long-term maintenance of knee function? Am J Sports Med. 2009;37(4):754-9.

2. Cahill BR. Osteochondritis dissecans of the knee: treatment of juvenile and adult forms. J Am Acad Orthop Surg. 1995;3(4):237-247.

3. Williams JS Jr, Bush-Joseph CA, Bach BR Jr. Osteochondritis dissecans of the knee. Am J Knee Surg. 1998;11(4):221-32.

4. Crawford DC, Safran MR. Osteochondritis dissecans of the knee. J Am Acad Orthop Surg. 4(3):123-33.

5. Fairbanks HAT. Osteochondritis dissecans. Br J Surg. 1933;21:67-82.

6. Flynn JM, Kocher MS, Ganley TJ. Osteochondritis dissecans of the knee. J Pediatr Orthop. 2004;24(4):434-43.

7. Smillie IS. Osteochondritis dissecans: loose body in joints. Edinburgh: Churchill Livingstone; 1960.

8. Stanitski CL, Bee J. Juvenile osteochondritis dissecans of the lateral femoral condyle after lateral discoid meniscal surgery. Am J Sports Med. 2004;32(3):797-801.

9. Reddy AS, Frederick RW. Evaluation of the intraosseous and extraosseous blood supply to the distal femoral condyles. Am J Sports Med. 1998;26(3):415-9.

10. Ribbing $S$. The hereditary multiple epiphyseal disturbance and its consequences for the aetiogenesis of local malacias--particularly the osteochondrosis dissecans. Acta Orthop Scand. 1955;24(4):286-99.

11. Mubarak SJ, Carroll NC. Familial osteochondritis dissecans of the knee. Clin Orthop Relat Res. 1979;(140):131-6.

12. Petrie PW. Aetiology of osteochondritis dissecans. Failure to establish avfamilial background. J Bone Joint Surg Br. 1977;59(3):366-7.

13. Caffey J, Madell Sh, Royer C, Morales P. Ossification of the distal femoral epiphysis. J Bone Joint Surg Am. 1958;40-A(3):647-54.

14. Guhl JF. Arthroscopic treatment of osteochondritis dissecans. Clin Orthop Relat Res. 1981;(167):65-74.

15. Detterline AJ, Goldstein JL, Rue JP, Bach BR Jr. Evaluation and treatment of osteochondritis dissecans lesions of the knee. J Knee Surg. 2008;21(2):106-15.

16. Hefti F, Beguiristain J, Krauspe R, Möller-Madsen B, Riccio V, Tschauner C, et al. Osteochondritis dissecans: a multicenter study of the European Pediatric Orthopedic Society. J Pediatr Orthop B. 1999;8(4):231-45.

17. Wilson JN. A diagnostic sign in osteochondritis dissecans of the knee. J Bone Joint Surg Am. 1967;49(3):477-80.

18. Conrad JM, Stanitski CL. Osteochondritis dissecans: Wilson's sign revisited. Am J Sports Med. 2003;31(5):777-8.

19. Johnson EW Jr, McLeod TL. Osteochondral fragments of the distal end of the femur fixed with bone pegs: report of two cases. J Bone Joint Surg Am. 1977;59(5):677-9.

20. Edwards DH, Bentley G. Osteochondritis dissecans patellae. J Bone Joint Surg Br. 1977;59(1):58-63.

21. Paletta GA Jr, Bednarz PA, Stanitski CL, Sandman GA, Stanitski DF, Kottamasu $S$. The prognostic value of quantitative bone scan in knee osteochondritis dissecans. A preliminary experience. Am J Sports Med. 1998;26(1):7-14.

22. Cahill BR, Berg BC. 99m-Technetium phosphate compound joint scintigraphy in the management of juvenile osteochondritis dissecans of the femoral condyles. Am J Sports Med. 1983;11(5):329-35.

23. Adachi N, Deie M, Nakamae A, Ishikawa M, Motoyama M, Ochi M. Functional and radiographic outcome of stable juvenile osteochondritis dissecans of the knee treated with retroarticular drilling without bone grafting. Arthroscopy. 2009;25(2):145-52.

24. Friel NA, Bajaj S, Cole JB. Articular cartilage injury and adult OCD: treatment options and decision making. In: Insall \& Scott. Surgery of the knee. Philadelphia: Churchill Livingstone Elsevier; 2012. p. 153-62.

25. Rodrigues MB, Camanho JL. Avaliação da cartilagem do joelho pela ressonância magnética. Rev Bras Ortop. 2010; 45(4):340-6.

26. Gebarski K, Hernandez RJ. Stage-I osteochondritis dissecans versus normal variants of ossification in the knee in children. Pediatr Radiol. 2005;35(9):880-6.

27. Pill SG, Ganley TJ, Milam RA, Lou JE, Meyer JS, Flynn JM. Role of magnetic resonance imaging and clinical criteria in predicting successful nonoperative treatment of osteochondritis dissecans in children. J Pediatr Orthop. 2003;23(1):102-8.

28. Kijowski R, Blankenbaker DG, Shinki K, Fine JP, Graf BK, De Smet AA. Juvenile versus adult osteochondritis dissecans of the knee: appropriate MR imaging criteria for instability. Radiology. 2008;248(2):571-8.

29. Wall EJ, Vourazeris J, Myer GD, Emery KH, Divine JG, Nick TG, et al. The healing potential of stable juvenile osteochondritis dissecans knee lesions. J Bone Joint Surg Am. 2008;90(12):2655-64.

30. Linden B. Osteochondritis dissecans of the femoral condyles: a long-term follow-up study. J Bone Joint Surg Am. 1977;59(6):769-76.

31. Twyman RS, Desai K, Aichroth PM. Osteochondritis dissecans of the knee. A long-term study. J Bone Joint Surg Br. 1991;73(3):461-4.

32. Liedl M, Sekiya JK. Treatment of juvenile osteochondritis dissecans of the knee. In: Insall \& Scott. Surgery of the knee. Philadelphia: Churchill Livingstone Elsevier; 2012. p. 235-41.

33. Sales de Gauzy J, Mansat C, Darodes PH, Cahuzac JP. Natural course of osteochondritis dissecans in children. J Pediatr Orthop B. 1999;8(1):26-8.

34. Donaldson LD, Wojtys EM. Extraarticular drilling for stable osteochondritis dissecans in the skeletally immature knee. J Pediatr Orthop. 2008;28(8):831-5.

35. McCarty LP 3rd. Primary repair of osteochondritis dissecans in the knee. In: Cole BJ, Sekiya JK, editors. Surgical techniques of shoulder, elbow and knee in sports medicine. Philadelphia: Saunders Elsevier; 2008. p. 517-26.

36. Lebolt JR, Wall EJ. Retroarticular drilling and bone grafting of juvenile osteochondritis dissecans of the knee. Arthroscopy. 2007;23(7):794.e1-4.

37. Ganley TJ, Flynn JM. Osteochondritis dissecans. In: Insall \& Scott. Surgery of the knee. Philadelphia: Churchill Livingstone Elsevier; 2006. p. 1234-41.

38. Alford JW, Cole BJ. Cartilage restoration, part 2: techniques, outcomes, and future directions. Am J Sports Med. 2005;33(3):443-60.

39. Krishnan SP, Skinner JA, Carrington RW, Flanagan AM, Briggs TW, Bentley G. Collagen-covered autologous chondrocyte implantation for osteochondritis dissecans of the knee: two- to seven-year results. J Bone Joint Surg Br. 2006;88(2):203-5.

40. Wright RW, McLean M, Matava MJ, Shively RA. Osteochondritis dissecans of the knee: long-term results of excision of the fragment. Clin Orthop Relat Res. 2004;(424):239-43.

41. Steadman JR, Rodkey WG, Briggs KK. Microfracture to treat full-thickness chondral defects: surgical technique, rehabilitation, and outcomes. J Knee Surg. 2002;15(3):170-6.

42. Mithoefer K, Williams RJ 3rd, Warren RF, Potter HG, Spock CR, Jones EC, et al. Chondral resurfacing of articular cartilage defects in the knee with the microfracture technique. Surgical technique. J Bone Joint Surg Am. 2006;88 (Suppl 1 Pt 2):294-304.

43. Kocher MS, Czarnecki JJ, Andersen JS, Micheli LJ. Internal fixation of juvenile osteochondritis dissecans lesions of the knee. Am J Sports Med. 2007;35(5):712-8.

44. Cole BJ, Lee SJ. Complex knee reconstruction: articular cartilage treatment options. Arthroscopy. 2003;19(Suppl 1):1-10.

45. Jani MM, Parker RD. Internal fixation devices for the treatment of unstable osteochondritis dissecans and chondral lesions. Oper Tech Sports Med. 2004; 12:170-5.

46. Lindholm S, Pylkkänen P, Osterman K. Fixation of osteochondral fragments in the knee joint. A clinical survey. Clin Orthop Relat Res. 1977;(126):256-60.

47. Gillespie HS, Day B. Bone peg fixation in the treatment of osteochondritis dissecans of the knee joint. Clin Orthop Relat Res. 1979;(143):125-30.

48. Navarro R, Cohen M, Filho MC, da Silva RT. The arthroscopic treatment of osteochondritis dissecans of the knee with autologous bone sticks. Arthroscopy. 2002;18(8):840-4.

49. Johnson LL, Uitvlugt G, Austin MD, Detrisac DA, Johnson C. Osteochondritis dissecans of the knee: arthroscopic compression screw fixation. Arthroscopy. 1990;6(3):179-89.

50. Dervin GF, Keene GC, Chissell HR. Biodegradable rods in adult osteochondritis dissecans of the knee. Clin Orthop Relat Res. 1998;(356):213-21.

51. Steadman JR, Briggs KK, Rodrigo JJ, Kocher MS, Gill TJ, Rodkey WG. Outcomes of microfracture for traumatic chondral defects of the knee: average 11-year follow-up. Arthroscopy. 2003;19(5):477-84.

52. Steadman JR, Rockey WG, Briggs KK. Microfracture technique in the knee. In: Cole BJ, Sekiya JK. Surgical techniques of shoulder, elbow and knee in sports medicine: Philadelphia: Saunders Elsevier; 2008. p. 509-15.

53. Mithoefer K, McAdams T, Williams RJ, Kreuz PC, Mandelbaum BR. Clinical efficacy of the microfracture technique for articular cartilage repair in the knee: an evidence-based systematic analysis. Am J Sports Med. 2009;37(10):2053-63.

54. Yamashita F, Sakakida K, Suzu F, Takai S. The transplantation of an autogeneic osteochondral fragment for osteochondritis dissecans of the knee. Clin Orthop Relat Res. 1985;(201):43-50.

55. Kish G, Módis L, Hangody L. Osteochondral mosaicplasty for the treatment of focal chondral and osteochondral lesions of the knee and talus in the athlete. Rationale, indications, techniques, and results. Clin Sports Med. 1999;18(1):45-66. 
56. Hangody L, Füles P. Autologous osteochondral mosaicplasty for the treatment of full-thickness defects of weight-bearing joints: ten years of experimental and clinical experience. J Bone Joint Surg Am. 2003;85(Suppl 2):25-32.

57. Miniaci A, Tytherleigh-Strong G. Fixation of unstable osteochondritis dissecans lesions of the knee using arthroscopic autogenous osteochondral grafting (mosaicplasty). Arthroscopy. 2007;23(8):845-51

58. Peterson L, Minas T, Brittberg M, Lindahl A. Treatment of osteochondritis dissecans of the knee with autologous chondrocyte transplantation: results at two to ten years. J Bone Joint Surg Am. 2003;85(Suppl 2):17-24.

59. Bentley G, Biant LC, Carrington RW, Akmal M, Goldberg A, Williams AM, et al. A prospective, randomised comparison of autologous chondrocyte implantation versus mosaicplasty for osteochondral defects in the knee. J Bone Joint Surg Br. 2003;85(2):223-30.

60. Knutsen G, Drogset JO, Engebretsen L, Grøntvedt T, Isaksen V, Ludvigsen TC, et al. A randomized trial comparing autologous chondrocyte implantation with microfracture. Findings at five years. J Bone Joint Surg Am. 2007;89(10):2105-12.

61. Bartlett W, Gooding CR, Carrington RW, Skinner JA, Briggs TW, Bentley G. Autologous chondrocyte implantation at the knee using a bilayer collagen membrane with bone graft. A preliminary report. J Bone Joint Surg $\mathrm{Br}$. 2005;87(3):330-2.

62. Fu FH, Zurakowski D, Browne JE, Mandelbaum B, Erggelet C, Moseley JB Jr, et al. Autologous chondrocyte implantation versus debridement for treatment of full-thickness chondral defects of the knee: an observational cohort study with 3-year follow-up. Am J Sports Med. 2005;33(11):1658-66.

63. LaPrade RF, Bursch LS, Olson EJ, Havlas V, Carlson CS. Histologic and immunohistochemical characteristics of failed articular cartilage resurfacing procedures for osteochondritis of the knee: a case series. Am J Sports Med. 2008;36(2):360-8.

64. Saris DB, Vanlauwe J, Victor J, Haspl M, Bohnsack M, Fortems Y, et al. Characterized chondrocyte implantation results in better structural repair when treating symptomatic cartilage defects of the knee in a randomized controlled trial versus microfracture. Am J Sports Med. 2008;36(2):235-46.

65. Safran MR, Seiber K. The evidence for surgical repair of articular cartilage in the knee. J Am Acad Orthop Surg. 2010;18(5):259-66.

66. Horas U, Pelinkovic D, Herr G, Aigner T, Schnettler R. Autologous chondrocyte implantation and osteochondral cylinder transplantation in cartilage repair of the knee joint. A prospective, comparative trial. J Bone Joint Surg Am. 2003;85(2):185-92.

67. Knutsen G, Engebretsen L, Ludvigsen TC, Drogset JO, Grøntvedt T, Solheim $\mathrm{E}$, et al. Autologous chondrocyte implantation compared with microfracture in the knee. A randomized trial. J Bone Joint Surg Am. 2004;86(3):455-64.

68. Gudas R, Kalesinskas RJ, Kimtys V, Stankevicius E, Toliusis V, Bernotavicius $\mathrm{G}$, et al. A prospective randomized clinical study of mosaic osteochondral autologous transplantation versus microfracture for the treatment of osteochondral defects in the knee joint in young athletes. Arthroscopy. 2005;21(9):1066-75.

69. Garrett JC. Fresh osteochondral allografts for treatment of articular defects in osteochondritis dissecans of the lateral femoral condyle in adults. Clin Orthop Relat Res. 1994;(303):33-7.

70. Gross AE. Repair of cartilage defects in the knee. J Knee Surg. 2002;15(3):167-9.

71. Fischer $M$, Koller $U$, Krismer $M$. The use of fresh allografts in osteochondrosis dissecans of the lateral femoral condyle. Oper Orthop Traumatol. 2006;18(3):245-58.

72. Emmerson BC, Görtz S, Jamali AA, Chung C, Amiel D, Bugbee WD. Fresh osteochondral allografting in the treatment of osteochondritis dissecans of the femoral condyle. Am J Sports Med. 2007;35(6):907-14.

73. McCulloch PC, Kang RW, Sobhy MH, Hayden JK, Cole BJ. Prospective evaluation of prolonged fresh osteochondral allograft transplantation of the femoral condyle: minimum 2-year follow-up. Am J Sports Med. 2007;35(3):411-20.

74. Chambers HG, Shea KG, Anderson AF, Brunelle TJ, Carey JL, Ganley TJ, et al. Diagnosis and treatment of osteochondritis dissecans. J Am Acad Orthop Surg. 2011;19(5):297-306

75. Kocher MS, DiCanzio J, Zurakowski D, Micheli LJ. Diagnostic performance of clinical examination and selective magnetic resonance imaging in the evaluation of intraarticular knee disorders in children and adolescents. Am J Sports Med. 2001;29(3):292-6.

76. Kocher MS, Micheli LJ, Yaniv M, Zurakowski D, Ames A, Adrignolo AA. Functional and radiographic outcome of juvenile osteochondritis dissecans of the knee treated with transarticular arthroscopic drilling. Am J Sports Med. 2001;29(5):562-6.

77. O'Connor MA, Palaniappan M, Khan N, Bruce CE. Osteochondritis dissecans of the knee in children. A comparison of MRI and arthroscopic findings. J Bone Joint Surg Br. 2002;84(2):258-62. 